\title{
Knowledge and Practice of Exclusive Breast Feeding Among Mothers in Gbarantoru Community, Bayelsa State, Nigeria
}

\author{
Oliemen Peterside*, Onyaye E Kunle-Olowu, Chika O Duru \\ Department of Paediatrics and Child Health, Niger Delta University Teaching Hospital, Okolobiri, Bayelsa \\ State, Nigeria
}

\begin{abstract}
Background: Exclusive breast feeding for the first six months of life significantly improves the growth, health status and survival of infants. However in spite of all the evidence in support of this practice, its prevalence in the developing world has remained low.

Aim: To determine the knowledge and practice of exclusive breastfeeding among mothers of infants aged 7 to 24 months in Gbarantoru Community, Bayelsa State, Nigeria in order to derive information to be used for future breast feeding enlightenment programmes in the sub-region.

Methodology: During a medical outreach organized by the Nigerian Medical Association, Bayelsa State Branch, 134 mothers of infants aged 7 to 24 months were interviewed on their knowledge and practice of exclusive breastfeeding.

Results: 59.7\% of the mothers knew the correct definition and duration of exclusive breastfeeding. The major source of their breast feeding knowledge was health workers (80.6\%), followed by the mass media (10.4\%). All (100\%) the mothers breast fed their babies in the first 6 months of life however only 26.9\% of them practiced exclusive breast feeding for 6 months. Exclusive breast feeding rate increased with increasing maternal age and education. Mothers who knew the benefits of exclusive breast feeding were more likely to breast feed exclusively compared to those who did not.

Conclusion: There is a wide gap between knowledge and practice of exclusive breast feeding among mothers in Gbarantoru Community. There is an urgent need for more programmes aimed at promoting exclusive breastfeeding as well as educating and re-educating health personnel and the general public

Key words: Exclusive breast feeding, knowledge, practice, benefits, mothers.
\end{abstract}

\section{Introduction}

Exclusive breastfeeding is defined as the practice of feeding an infant with breast milk only excluding water, other liquids, breast milk substitutes and solid foods. Vitamin drops, minerals, oral rehydration solution (ORS) and medicines may be given, ${ }^{1}$ Current World Health Organization (WHO) and United Nations Children Fund (UNICEF) recommendation for optimal infant feeding are exclusive breastfeeding for the first six months after which complementary foods should be introduced with continuation of breastfeeding until two years or beyond. ${ }^{2}$ Exclusive breastfeeding is an affordable and feasible intervention that improves new born survival and has been identified as one of the most natural forms of preventive medicine. ${ }^{3}$ It fulfills the nutritional requirements of the infants and protects them from infections like diarrhoea and pneumonia. ${ }^{4}$ Results of a simulation study representing $90 \%$ of worldwide deaths among children less than five years suggest that universal coverage with breastfeeding may help prevent $13 \%$ of all child deaths. ${ }^{5}$ Not only is human breast milk ideal for the human infant because of its nutritive and anti-infective properties, it also provides physical contact between a mother and her baby further strengthening the emotional bond between them. ${ }^{6}$

Exclusive breast feeding apart from being beneficial to the baby, has also been shown to have significant short and long term health benefits for the mother. ${ }^{7}$ It is associated with lactational amenorrhoea which is an important choice for postpartum family planning. ${ }^{8}$ Also mothers who do not breast feed are more likely to develop postpartum depression, obesity, type 2 diabetes mellitus, breast cancer and hypertension. ${ }^{9}$

The benefits of exclusive breast feeding are well established especially in poor communities where early introduction of foods other than breast milk is of particular concern because of the risk of pathogen contamination and inadequate preparation of breast milk substitutes leading to increased risk of morbidity and malnutrition. ${ }^{6}$ However, despite the high prevalence of childhood malnutrition and proven benefits of exclusive breastfeeding, the practice of breastfeeding has markedly declined throughout the developing world. ${ }^{10}$ According to a recent worldwide WHO estimate only 35\% of children between birth and 5 months of age are breast fed exclusively ${ }^{11}$ and in Nigeria, exclusive breastfeeding rates for six months have dropped from $17.2 \%$ in 2003 to $13.0 \%$ in $2008 .^{12}$ These figures are far below the $90 \%$ level recommended by the WHO. ${ }^{5}$

Breastfeeding practices and attitudes have been shown to be influenced by demographic, biophysical, social, cultural and psychological factors. ${ }^{13-14}$ Several studies ${ }^{15-22}$ have demonstrated that mothers with good knowledge of exclusive breastfeeding are more likely to breastfeed their infants exclusively in the first six 
months of life. The present study was therefore carried out in Gbarantoru, a rural community in the Delta region of Southern Nigeria with the aim of ascertaining the knowledge and practice of exclusive breastfeeding in order to derive useful information for the planning of exclusive breastfeeding sensitization campaigns in the region.

\section{Ethical consideration}

\section{Methodology}

Ethical approval for the study was obtained from the research and ethics committee of the Niger Delta University Teaching Hospital Okolobiri, Bayelsa State. Permission for the study was obtained from the council of Chiefs, Gbarantoru community and verbal consent was obtained from the study participants.

\section{Study area}

Gbarantoru is a rural community in Bayelsa State, Southern Nigeria. It is located about 8km from Yenagoa, the capital city of Bayelsa State and is accessible by road. It has an estimated population of 3,351 people. The community has a primary health centre which is manned by a Youth Corp doctor, two midwives and 4 community health workers. Services offered at the health centre include maternal and child health services including antenatal care, delivery and immunization services.

\section{Sampling}

This was a cross sectional descriptive study carried out on the $20^{\text {th }}$ of August 2013, during a medical outreach conducted by the Nigerian Medical Association (NMA), Bayelsa State branch in Gbarantoru Community. All mothers that presented with children aged seven to twenty four months were recruited into the study. The study participants had free medical consultation and drugs. The investigators administered and filled questionnaires which included the mothers' age, occupation, educational status, number of children and marital status. All mothers were asked to define exclusive breastfeeding and this was written in their own words. For the mothers that had heard about exclusive breastfeeding, their source of knowledge was recorded. The mothers were asked to list the benefits of exclusive breastfeeding to the baby and mother. Each mother was assessed for practice and duration of exclusive breastfeeding. For those that did not breast feed exclusively, their reasons were obtained and recorded.

\section{Data analysis}

Data was entered onto an excel spreadsheet and presented in form of tables. Data was analyzed using epi-info version 6.04 and SPSS version 15 statistical packages. Test of significance between proportions was assessed using Chi-square. A 95\% confidence interval was used and a p value of less than 0.05 was considered significant.

\section{Results}

General characteristics of the mothers: Age range, marital status and educational level

One hundred and thirty four mothers with children aged 7 to 24 months were interviewed. As shown in table $1,50(37.3 \%)$ of the mothers were in the 25 to 29 years age category followed by $36(26.9 \%)$ in the 20 to 24 years and $18(13.4 \%)$ in the 35 to 39 years age categories respectively. Eighty six $(64.2 \%)$ of the mothers were married while $38(35.8 \%)$ of them were single. Over half of the mothers [80 (59.7\%)] had secondary level of education followed by $40(29.9 \%)$ of them with primary education.

Table 1: Age range, marital status and educational level of the mothers

\begin{tabular}{lcc}
\hline $\begin{array}{l}\text { Age range } \\
\text { (years) }\end{array}$ & Number & Percentage of total population \\
\hline $15-19$ & 8 & 6.0 \\
$20-24$ & 36 & 26.9 \\
$25-29$ & 50 & 37.3 \\
$30-34$ & 14 & 10.4 \\
$35-39$ & 18 & 13.4 \\
$40-44$ & 4 & 3.0 \\
$45-49$ & 4 & 3.0 \\
Total & 134 & 100 \\
\hline Marital status & & \\
Married & 86 & 64.2 \\
Single & 48 & 35.8 \\
Total & 134 & 100 \\
\hline Educational level & & \\
None & 8 & 6.0 \\
Primary & 40 & 29.9 \\
Secondary & 80 & 59.7 \\
Tertiary & 6 & 4.5 \\
Total & 134 & 100 \\
\hline
\end{tabular}




\section{General characteristics of the mothers: Parity and occupation}

One hundred and ten $(82.1 \%)$ of the mothers were multipara while $24(17.9 \%)$ of them were primipara (table 2).The highest percentage of the mothers $35.8 \%$ were unemployed, followed by $31.3 \%$ and $7.5 \%$ who were traders and seamstresses respectively.

Table 2: Parity and occupation of the mothers

\begin{tabular}{lcc}
\hline Parity & Number & Percentage \\
\hline Primipara & 24 & 17.9 \\
Multipara & 110 & 82.1 \\
Total & 134 & 100 \\
\hline Occupation & & \\
Unemployed & 48 & 35.8 \\
Trader & 42 & 31.3 \\
Seamstress & 10 & 7.5 \\
Hair dresser & 8 & 6.0 \\
University student & 8 & 6.0 \\
Civil servant/Clerk & 6 & 4.5 \\
Teacher & 6 & 4.5 \\
Farmer & 6 & 4.5 \\
Total & 134 & 100 \\
\hline
\end{tabular}

\section{Exclusive breastfeeding knowledge}

As shown in table 3, $80(59.7 \%)$ of the mothers knew the correct definition and duration of exclusive breastfeeding while 26 (19.4\%) had never heard of exclusive breastfeeding.

\section{Source of exclusive breast feeding knowledge}

One hundred and eight $(80.6 \%)$ of the mothers heard about exclusive breast feeding from health workers during antenatal clinic visits, $14(10.4 \%)$ heard about it from either the television or radio and 12 $(9.0 \%)$ heard about exclusive breast feeding from relatives and/or friends (table 3 ).

Table 3: Mothers definition of Exclusive breast feeding

\begin{tabular}{lcc}
\hline Definition & Number & Percentage \\
\hline Breast milk only for 6 months & 80 & 59.7 \\
No idea & 26 & 19.4 \\
Breast milk and water for 6 months & 10 & 7.5 \\
Breast milk only for unknown duration & 6 & 4.5 \\
Breast milk only for 3 to six months & 4 & 3.0 \\
Breast feeding baby constantly & 4 & 3.0 \\
Breast milk and water for 3 to six months & 2 & 1.5 \\
Breast milk only for 7 months & 2 & 1.5 \\
Total & $\mathbf{1 3 4}$ & $\mathbf{1 0 0}$ \\
\hline Source of exclusive breast feeding knowledge & & 80.6 \\
Health workers & 108 & 10.4 \\
Mass media (television/radio) & 14 & 9.0 \\
Relatives/friends & 12 & $\mathbf{1 0 0}$ \\
Total & $\mathbf{1 3 4}$ & \\
\hline
\end{tabular}

\section{Knowledge of benefits of exclusive breastfeeding to baby and mother}

Ninety eight $(73.1 \%)$ knew at least one benefit of exclusive breast feeding to the baby while 36 (26.9\%) had no idea that exclusive breastfeeding had any benefit to the baby. Forty two (31.3\%) thought exclusive breastfeeding had benefits to the mother while $92(68.7 \%)$ did not. The various benefits of exclusive breast feeding to the baby and mother mentioned by the mothers are listed in table 4 .

Thirty four $(34.7 \%)$ of the 98 who knew at least one benefit of exclusive breastfeeding to the baby breastfed exclusively for 6 months while $2(5.6 \%)$ of the 36 who did not know any benefit to the baby practiced exclusive breast feeding. This difference was statistically significant $\left(\chi^{2} 11.38\right.$, $\mathrm{p}$ value 0.001$)$.

Twenty $(47.6 \%)$ of the 42 mothers who thought exclusive breast feeding had benefits to the mother practiced exclusive breastfeeding for 6 months as against $16(17.4 \%)$ of the 92 who did not know of any advantages to the mother. This difference was statistically significant $\left(\chi^{2} 13.41, p\right.$ value 0.000$)$.

Table 4: Benefits of exclusive breastfeeding to the baby and mother

\begin{tabular}{lcc}
\hline Advantage to baby & Number & Percentage \\
\hline Prevents illness & 48 & 35.8 \\
Makes baby healthy & 44 & 32.8 \\
Makes baby intelligent & 28 & 20.9 \\
Makes baby strong & 20 & 14.9 \\
Helps baby grow well & 20 & 14.9 \\
\hline
\end{tabular}


Knowledge And Practice Of Exclusive Breast Feeding Among Mothers In Gbarantoru Community,

\begin{tabular}{lcc}
\hline Prevents diarrhoea & 8 & 6.0 \\
Aids bonding between mother and child & 4 & 3.0 \\
Prevents infection & 4 & 3.0 \\
Prevents skin rashes & 2 & 1.5 \\
\hline Advantages to mother & & \\
Improves mothers appetite & 12 & 9.0 \\
Makes mother healthy/prevents illness/strong & 10 & 7.5 \\
Helps in child spacing & 8 & 6.0 \\
Saves cost & 8 & 6.0 \\
Prevents breast cancer & 2 & 1.5 \\
Cannot remember any & 2 & 1.5 \\
It is more convenient & 2 & 1.5 \\
Aids uterine contraction & 1 & 0.7 \\
Prevents pain in the breast & 1 & 0.7 \\
\hline
\end{tabular}

\section{Exclusive breastfeeding practice}

All $134(100 \%)$ of the mothers breastfed their babies within the first 6 months of life. However 60 (44.8\%) of them breastfed exclusively for 3 to 6 months with a mean duration of 5.4 months. Thirty six of the 134 mothers breast fed exclusively for 6 months giving an exclusive breast feeding rate of $26.9 \%$, fourteen (10.4\%) breastfed exclusively for 3 months, $8(6.0 \%)$ for 4 months and $2(1.5 \%)$ for 5 months.

Exclusive breastfeeding rate according to age range, marital status and educational level of the mothers

The exclusive breastfeeding rate increased with increasing maternal age from $0.0 \%$ among mothers aged 15 to 19 years to $100.0 \%$ among those aged 44 to 49 years (table 5).

Fourteen (16.3\%) of the 86 married mothers breastfed exclusively while $22(45.8 \%)$ of the 48 single mothers breastfed exclusively. This difference was statistically significant $\left(\chi^{2} 13.69, \mathrm{p}\right.$ value 0.000$)$.

The exclusive breast feeding rate showed a steady increase with increasing level of maternal education from $0.0 \%$ among the mothers with no formal education to $25.0 \%$ among those with primary level of education and $30.0 \%$ and $33.3 \%$ among the mothers with secondary and tertiary levels of education respectively. This difference was however not statistically significant $\left(\chi^{2} 3.54, \mathrm{p}\right.$ value 0.316$)$.

Table 5: Exclusive breastfeeding rate according to age range, marital status and educational level of the mothers

\begin{tabular}{lccc}
\hline $\begin{array}{l}\text { Age range } \\
\text { (years) }\end{array}$ & Number & $\begin{array}{c}\text { Number who breastfed } \\
\text { exclusively for 6 months }\end{array}$ & $\begin{array}{c}\text { Percentage who breastfed } \\
\text { exclusively }\end{array}$ \\
\hline $15-19$ & 8 & 0 & $0.0 \%$ \\
$20-24$ & 36 & 6 & 16.7 \\
$25-29$ & 50 & 18 & 36.0 \\
$30-34$ & 14 & 2 & 14.3 \\
$35-39$ & 18 & 4 & 22.2 \\
$40-44$ & 4 & 2 & 50.0 \\
$45-49$ & 4 & 4 & 100.0 \\
\hline Marital status & & & 16.3 \\
Married & 86 & 14 & 45.8 \\
Single & 48 & 22 & 0.0 \\
\hline Educational level & & 0 & 25.0 \\
None & 8 & 10 & 30.0 \\
Primary & 40 & 24 & 33.3 \\
Secondary & 80 & 2 & \\
Tertiary & 6 & & \\
\hline
\end{tabular}

Exclusive breast feeding rate according to parity and occupation of the mothers

As shown in table 6, $30(27.3 \%)$ of the 110 multiparous mothers breastfed exclusively compared to 6 $(25.0 \%)$ of the 24 primiparous mothers. This difference was not statistically significant $\left(\chi^{2} 0.02, \mathrm{p}\right.$ value $0.0 .884)$.

The exclusive breastfeeding rate was highest among civil servants and farmers (66.7\%) followed by seamstresses $(40.0 \%)$, traders and teachers with exclusive breastfeeding rates of $33.3 \%$ respectively (table 6).

Table 6: Exclusive breast feeding rate according to parity and occupation of the mothers

\begin{tabular}{lccc}
\hline Parity & Number & $\begin{array}{c}\text { Number who breastfed exclusively } \\
\text { for 6 months }\end{array}$ & $\begin{array}{c}\text { Percentage who breastfed } \\
\text { exclusively }\end{array}$ \\
\hline Primipara & 24 & 6 & 25.0 \\
Multipara & 110 & 30 & 27.3 \\
\hline Occupation & & & \\
Housewife/Unemployed & 48 & 6 & 12.5 \\
Trader & 42 & 14 & 33.3 \\
Seamstress & 10 & 4 & 40.0 \\
\hline
\end{tabular}


Knowledge And Practice Of Exclusive Breast Feeding Among Mothers In Gbarantoru Community,

\begin{tabular}{llcc}
\hline & & & \\
\hline Hair dresser & 8 & 0 & 0.0 \\
University student & 8 & 2 & 25.0 \\
Civil servant/Clerk & 6 & 4 & 66.7 \\
Teacher & 6 & 2 & 33.3 \\
Farmer & 6 & 4 & 66.7 \\
\hline
\end{tabular}

\section{Reasons for not breastfeeding exclusively}

As shown in table 7, 68 (50.7\%) of the mothers did not breast feed exclusively because they thought their breast milk was not enough for the baby, followed by 16 (11.9\%) who thought all babies need to drink water and $14(10.4 \%)$ who did not breast feed exclusively because of advice from friends/relatives.

Table 7: Reasons for not breastfeeding exclusively

\begin{tabular}{lcc}
\hline Reason & Number & Percentage \\
\hline Breast milk not enough for baby & 68 & 50.7 \\
All babies need to drink water & 16 & 11.9 \\
Advice from friends/relatives & 14 & 10.4 \\
My baby was always crying & 8 & 6.0 \\
Exclusive breast feeding is too demanding & 8 & 6.0 \\
Not convenient because of my job & 6 & 4.5 \\
I was lactating poorly & 6 & 4.5 \\
I do not eat well enough to breast feed exclusively & 4 & 3.0 \\
Because of my ill health & 4 & 3.0 \\
It is our culture to give water to breastfeeding babies & 3 & 2.2 \\
The baby's father insisted on addition of infant formula & 3 & 2.2 \\
I have never heard of exclusive breastfeeding & 2 & 1.5 \\
I could not cope because I had twins & 1 & 0.7 \\
\hline
\end{tabular}

\section{Discussion}

As shown in the present study, 59.7\% of the mothers in Gbarantoru community of Bayelsa State knew the correct definition and duration of exclusive breast feeding. This is similar to the $50 \%$ knowledge reported by Okolie $\mathrm{U}^{19}$ in Enugu. Ukaegbuet $\mathrm{al}^{18}$ however reported a higher knowledge of $91.2 \%$ among mothers attending the immunization clinic of the NnamdiAzikiwe University Teaching Hospital, Nigeria. This difference may be due to the fact that Ukaegbu's study population were urban dwellers whereas the population in the present study were rural dwellers. It has been demonstrated that women living in urban areas have better knowledge of exclusive breast feeding compared to women in rural areas. ${ }^{23-24}$ The $59.7 \%$ knowledge of exclusive breastfeeding in the present study is higher than $35.3 \%$ reported by Abdul Ameer et $\mathrm{al}^{22}$ in Iraq. The reason for this difference is not immediately clear but may be due to geographical and cultural differences between the two study populations.

The major source of information on exclusive breast feeding to the mothers in the present study was health workers. This is similar to reports by Ukaegbu et al ${ }^{18}$ and El-Kariri and Kanoa. ${ }^{25}$ It has been shown that the key to successful breastfeeding is based on information, education and communication strategies aimed at behavior change ${ }^{16}$ with improved health care practices standing out as being the most promising means of reinforcing the prevalence and duration of breast feeding. ${ }^{26}$ Though Health workers knowledge and attitude have been identified as a major factor influencing exclusive breastfeeding rates in some communities ${ }^{27-29}$ one wonders if these health workers are actually giving the mothers correct exclusive breast feeding information. Okolo and Ogbonna ${ }^{30}$ carried out a study to assess the knowledge, attitude and practice of health workers towards baby friendly hospital initiative in Keffi Local Government Area of Nigeria. They reported a low level of knowledge with $80.8 \%$ of them believing that babies less than 6 months on breast milk should also be given water. Benjamin ${ }^{31}$ in Washington, USA also opined that health workers including doctors and Nurses have surprisingly little training in lactation and lactation support. Schanler et $\mathrm{al}^{32}$ carried out a study on the educational needs of Paediatricians in the United States regarding breastfeeding. They reported that exclusive breastfeeding for the first month of life was recommended by $65 \%$ of the Paediatricians. The majority of the Paediatricians had not attended any presentation on breast feeding management in the preceding three years and most of them wanted more education on breast feeding management.

Apart from health workers, $10.4 \%$ of the mothers heard about exclusive breastfeeding from the television or radio. This highlights the importance of using the mass media as an alternative means of disseminating health information since about $46.8 \%$ of Nigerian mothers deliver outside health facilities ${ }^{30}$ and as such, may not have the privilege of getting infant feeding information from health workers. In Columbia, the use of mass media was assessed as being more effective in reaching pregnant women and breastfeeding mothers than health and educational agents. ${ }^{33}$ Gupta et $\mathrm{al}^{10}$ carried out a study in Uganda on evaluation of the extent to which exposure to communication messages in the media on behavioral change determined recent improvement in exclusive breastfeeding knowledge. Their reports indicated that exposure to these messages was strongly associated with women's knowledge of six months as the ideal duration for exclusive breast feeding. Positive 
influences on knowledge of men were also reported. The fact that almost half of Nigerian mothers deliver outside health facilities also highlights the need for community awareness programmes on exclusive breastfeeding which was demonstrated to increase knowledge of exclusive breastfeeding from $67.1 \%$ to $89.5 \%$ in a study done in fourteen Angawari centres in Chandigarh India. ${ }^{34}$

Though all the mothers in the present study breastfed their babies within the first six months of life, only $26.9 \%$ of them breast fed exclusively for 6 months. This is not surprising as it has been found that in the developing world, breastfeeding is nearly universal among mothers but not exclusive breastfeeding as early supplementation with water and other fluids and food is the norm. ${ }^{24}$ The exclusive breastfeeding rate of $26.9 \%$ though higher than the 2008 Nigerian national exclusive breast feeding prevalence of $13.0 \%$, ${ }^{12}$ is far below the WHO recommended prevalence of $90 \%{ }^{5}$ This shows a wide gap between desired and actual exclusive breast feeding practice which has also been demonstrated by other studies. ${ }^{20}$ Ekanem et al ${ }^{17}$ reported a similar exclusive breast feeding rate of $24.0 \%$ among working mothers in Calabar while Agunbiade et $\mathrm{a}^{35}$ reported a slightly lower rate of $19 \%$ among mothers in South-west Nigeria. Maduforo et $\mathrm{al}^{36}$ in Owerri however, reported a much higher exclusive breastfeeding practice rate of $66.4 \%$ among lactating women in Owerri Metropolis. Their higher exclusive breast feeding rate may be due to the fact that they also had a higher exclusive breast feeding knowledge of $90.6 \%$ as compared to the $59.7 \%$ found in the present study. According to Bryne et $\mathrm{al}^{37}$ mothers knowledge of exclusive breast feeding, determines their practice.

Results of the present study show that mothers with good knowledge of the benefits of exclusive breast feeding were more likely to breast feed exclusively. This is similar to reports from other studies in Nigeria ${ }^{18} \mathrm{Sri}-$ Lanka ${ }^{22}$ and Ireland. ${ }^{15}$ This finding is not surprising as it has been demonstrated that high maternal knowledge about infant health benefits from breastfeeding was directly related to maternal intention to exclusively breast feed. ${ }^{38}$ Also several studies ${ }^{36,39-41}$ which show high maternal knowledge of exclusive breast feeding also report high exclusive breast feeding rates whereas those ${ }^{20,42}$ with low maternal knowledge also report low exclusive breastfeeding practice rate.

Exclusive breast feeding rate in the present study increased with increasing maternal age and educational level. This is similar to reports from other Nigerian studies. ${ }^{17,18,43}$ This may be explained by the fact that younger mothers may practice exclusive breast feeding less as a result of inexperience which may make them more susceptible to family pressure.$^{17}$ It is also possible that with age, mothers may acquire experience and confidence in good child care practices and are less likely to be influenced by friends and relatives. ${ }^{18}$ Educated mothers may have better breast feeding practices because they are better able to understand the health implications. ${ }^{17}$

\section{Conclusion}

Though the practice of breastfeeding in Gbarantoru community is high, the exclusive breastfeeding rate is still low. There is an urgent need for more programmes aimed at promoting exclusive breastfeeding as well as educating and re-educating health personnel as well as members of the public. Exclusive breast feeding information programmes should not only include the definition and recommended duration but should also include its benefits to the infant, mother, family and community.

\section{Acknowledgement}

We thank the Nigerian Medical Association, Bayelsa State branch for organizing the medical outreach during which the study was conducted. We also thank the council of Chiefs of Gbarantoru community for their cooperation and for sensitizing members of the community to attend the medical outreach.

\section{References}

[1]. World Health Organization Part I. Definitions. Indicators for defining infant and young child feeding practices: Conclusions of a consensus meeting held 6-8 November 2007 in Washindton DC, USA. Available at http://whqlibdoc.who.int/publications/2008/9789241596664 eng.pdf.

[2]. WHO. The global strategy on infant and young child feeding. A joint WHO?UNICEF statement. World Health Organization Geneva, Switzerland 2003.

[3]. WHO collaborative study team on the role of breastfeeding on the prevention of infant mortality. Effect of breast feeding on infant and child mortality due to infectious diseases in less developed countries: a pooled analysis. Lancet 2000; $355: 451-455$

[4]. World Health Organization: Infant and young child feeding (IYCF) model chapter for textbooks for medical students and allied health professionals. Switzerland: World Health Organization; 2009.

[5]. Jones G, Steketle RW, Black RE, Bhutta ZA, Morris SS, Bellagio child survival strategy group. How many child deaths can we prevent this year? Lancet 2003; 362: $65-71$.

[6]. Victoria CG, smith PG, Vaughan JP, Nobre LC, Lombardi C, Teixeira AMB. Evidence for protection by breastfeeding against infant deaths from infectious disease in Brazil. Lancet 1987; 2: $319-322$.

[7]. Ip S, Chung M, Raman G. "Breast feeding and maternal and infant health outcomes in developed countries". Evidence Report/Technology Assessment 2007; 153: 1 - 186.

[8]. Thappa S, Short R, Potts M. Breast feeding, birth spacing and their effects on child survival. Nature 1988; $335: 679$ - 682. 


\section{Knowledge And Practice Of Exclusive Breast Feeding Among Mothers In Gbarantoru Community,}

[9]. HortaBernado L, Bahl R, Martinez Hose C, Victoria Cesar G. evidence on the long term effects of breast feeding: systematic reviews and meta-analysis. World Health Organization 2007. Available http://whqlibdoc.who.int/publications/2007/9789241595230_eng.pdf.

[10]. Gupta N, Katende C, Bassinger R. an evaluation of post-campaign knowledge and practices of exclusive breastfeeding in Uganda. J Health PopulNutr 2004; 22(4): 429 - 439.

[11]. World Health Organization: the state of breastfeeding in 33 countries. 2010. Available at: http://www.worldbreastfeedingtrends.org.

[12]. National Population Commision (NPC) and ICF Macro: National demographic and Health Survey 2008 Calverton, Maryland, USA: NPC and ICF Macro; 2009.

[13]. Thulier D, Mercer J. variables associated with breastfeeding duration. J ObstetGynecol Neonatal Nurs 2009; $38(3): 259$ - 268.

[14]. Dennis CL. Breast feeding initiation and duration: a 1990 - 2000 literature review. J ObstetGynecol Neonatal Nurs 2002; 31 (1): 12 -32 .

[15]. Zhou Q, Younger KM, Kearney JM. An exploration of the knowledge and attitudes towards breastfeeding among a sample of Chinese mothers in Ireland. BMC Public Health 2010; 10: 722.

[16]. Maheswari E, Vishnu BB, Mohammed APA. Knowledge, attitude and practice of breast feeding among post natal mothers. CurrPediatr Res 2010; 14(2): $119-124$

[17]. Ekanem IA, Ekanem AP, Asuquo A. Attitude of working mothers to exclusive breastfeeding in Calabar Municipality, Cross Rivers State, Nigeria. J Food Res 2012; 1(2): $71-75$.

[18]. Ukaegbu AU, Ukaegbu PO, Onyeonoro UU, Ubajaka CF. Determinants of breastfeeding among mothers in Anambra State, Nigeria. South Afr J Child Health 2011; 5(4): 112 - 116

[19]. Okolie U. Problems encountered by breast feeding mothers in their practice of exclusive breastfeeding in tertiary hospitals in Enugu State, South-East Nigeria. Int J NutrMetabol 2012; 4(8): 107 - 113.

[20]. Chaudhary RN, Shah T, Raja S. Knowledge and practice of mothers regarding breastfeeding: a hospital based study. KnowlPract Breastfeeding 2011: 9 (3): $194-200$.

[21]. Oche MO, Umar AS, Ahmed H. Knowledge and practice of exclusive breastfeeding in Kware, Nigeria. Afr Health Sci 2011; 11(3): $518-523$.

[22]. Agampodi SB, Agampodi TC, Piyaseeli UK. Breastfeeding practices in a public health field practice area in Sri Lanka: a survival analysis. Int breastfeeding $\mathrm{J} 2007 ; 11: 2-13$

[23]. Abdul Ameer AJ, Al-Hali AHM, Abdulla MM. Knowledge, attitudes and practices of Iraqi mothers and family child-caring women regarding breastfeeding. East Meditter Health J 2008; 14(5): 1003 - 1014

[24]. Khamnian Z, Azarfar A, Ravanshad Y, Hashemian M, Hasanpour K. Exclusive breast feeding and factors affecting knowledge, attitude and practice of mothers in rural and urban regions of East Azerbaijan, Iran. Life Sci J 2013; $10(5 \mathrm{~s}): 473-478$.

[25]. El-Kariri M, Kanoa B. Infant feeding in Gaza strip: mother knowledge, attitudes and practices. Ann Alqud Med 2007; $3: 58$ - 65.

[26]. Popkin B, Canahuatti J, Bailey PE, Ogara C. An evealuation of a national breastfeeding promotion programme in Honduras. J biosocSci 1991; 23: $5-21$.

[27]. Ekele BA, Ahmed H. exclusive breastfeeding. Hospital or Home practice. Nig Med Pract 1997; 33: 62.

[28]. Ogbonna C, Okolo SN, Eziogu A. Factors influencing exclusive breastfeeding in Jos, Plateau State, Nigeria. West Afri J Med 2000; 107.

[29]. Malami SA. Knowledge, attitude and practice of exclusive breastfeeding among nursing mothers in AkwaIbom State of Nigeria. Nig Med Pract 1995; 30: $2-3$

[30]. Okolo SN, Ogbonna C. Knowledge, attitude and practice of health workers in Keffi Local Government hospitals regarding BabyFriendly Hospital Initiative (BFHI) practices. Eur J ClinNutr 2002; 56: 438 - 441.

[31]. Benjamin RM. US Department of Health and Human Services. The Surgeon General's call to action to support breastfeeding. Washington D.C, US. 2011.

[32]. Schanler RJ, O’Connor KG, Lawrence RA. Pediatrics 1999; 103: e35.

[33]. Restrapo S. A multi-media strategy for a breastfeeding campaign in Columbia. Educ Broadcast Int 1981; $14: 30$ - 34

[34]. Galhotra A, Abrol A, Agarwal N, Goel N, Swami H. Impact of community based awareness campaigns on breastfeeding among lactating women in Chandigarh. Int J Health 2008; 7

[35]. Agunbiade OM, Ogunleye OV. Constraints to exclusive breastfeeding practice among breastfeeding mothers in South-west Nigeria: implications for scaling up. Int breastfeeding J 2012; 7: 5 .

[36]. Maduforo AN, Ubah NC, Obiako-Okeke PN. The practice of exclusive breastfeeding by lactating women in Owerri metropolis, Imo State, Nigeria. Glob Adv Res J Med MedSci 2013; 2(1): 013 - 019.

[37]. Bryne JP, Crowther CA, Moss JR. Factors associated with exclusive breastfeeding in children under 4 months old in Botacatu-SP, Brazil. Rev Latino-am Enferma-gem 1998; 15: 62 - 69.

[38]. Stuebe Am, Bonuck K. What predicts intent to breastfeed exclusively? Breastfeeding knowledge, attitudes and beliefs in a diverse urban population. Breastfeeding Med 2011; 6(6): 413 - 420

[39]. Sriram S, Soni P, Thanvi R, Prajapati N, Mehariya KM. knowledge, attitude and practices of mothers regarding infant feeding practices. Nat J Med Res 2013; 3(2): 147 - 150.

[40]. KamalDhammika BL, Gunawardena NS. Knowledge, practices and concerns regarding exclusive breastfeeding for six months among mothers of infants in a suburban setting in Sri Lanka. J Child Health 2012; 41(1): 9 - 14

[41]. Utoo BT, Ochejele S, Obulu MA, Utoo PM. Breastfeeding knowledge and attitude amongst Health workers in a Health care facility in South-South Nigeria: the need for middle level health manpower development. Clin Mother Child Health 2012; 9: doi: $10.4303 / \mathrm{cmch} / 235565$.

[42]. Motee A, Ramasawmy D, Pugo-Gunsam P, Jeewon R. An assessment of the breastfeeding practices and infant feeding pattern among mothers in Mauritius. J NutrMetabol 2013; article ID 243852, 8 pages http://dx.doi.org/10.1155/2013/243852.

[43]. Umar AS, Oche MO. Breastfeeding and weaning practices in an urban slum, North-Western Nigeria. Int J Trop Dis Health 2013; $3(2): 114-125$. 